\title{
STRATEGIC ISSUES AND DETERMINANT FACTORS OF AN INTERORGANIZATIONAL MACROCULTURE IN THE LODGING INDUSTRY
}

\author{
JOHN W. O'NEILL \\ Pennsylvania State University \\ LAURA L. BEAUVAIS \\ RICHARD W. SCHOLL \\ University of Rhode Island
}

This article presents an empirical study of lodging industry executives' beliefs regarding strategic issues that they consider to be most important. We theorize that fundamental factors exist indicating certain commonalties regarding executives' mental models about strategic issues. The possible influence of an industry macroculture is investigated as a source of similarity of mental models among executives competing in the lodging industry, and hypotheses are developed and tested regarding the sources of the macroculture. The results of an exploratory factor analysis indicate that among 20 potential strategic issues rated by executives in the study, 3 fundamental strategic directions exist. Furthermore, the results of the study indicate that professional journals, associations, conferences, and previous employment may be sources of the macroculture. Implications for research and practice are presented.

KEYWORDS: organizational culture; macroculture; mental model; strategic management; strategic issue; decision-making; lodging

Hospitality organization strategy and its development are important parts of the hospitality and management literature (e.g., Okumus, 2002; Olsen \& Roper, 1998). As lodging executives attempt to improve on the performance of their organizations in a highly competitive environment, they are continually addressing issues of competitive advantage, distinctive competency, and competitive

Authors' Note: The authors gratefully acknowledge the assistance of the following individuals and organizations: Steve Rushmore, HVS International; Fred Schwartz, Asian-American Hotel Owners Association; Doug Viehland, American Hotel \& Lodging Foundation.

Journal of Hospitality \& Tourism Research, Vol. xx, No. x, Month 2004, 1DOI: $10.1177 / 1096348004267517$

(C) 2004 International Council on Hotel, Restaurant and Institutional Education 
strategy. Organizational strategy represents a stream of decisions that are collective, unstructured, and consequential (Mintzberg, 1978). Such decisions are collective because each potential solution often hinges on the decisions of various subunits and decision-making groups who are involved in the day-to-day operation of the organization. They are unstructured because the problems they address involve multiple courses of action whose outcomes are difficult to evaluate. They are consequential because such decisions shape the long-term course of the firm (Eisenhardt \& Zbaracki, 1992).

Our research focuses on the areas of strategic management and decision making, two areas that are intertwined (Miller, Hickson, \& Wilson, 1999). Conceptually, strategic decision making may be viewed as a continuum from deliberate to emergent (Mintzberg \& Waters, 1985), which reflects two alternative descriptions of the strategic decision process. These include rational decision-making models in which strategic decision making is viewed as the result of a comprehensive analysis of information and the selection of activities to meet a prescribed goal, and incremental models that portray strategic decision making as a noncomprehensive process. These normative approaches have focused on analytic techniques that enable decision makers/top managers to match internal strengths and weaknesses with environmental opportunities and demands (e.g., David, 2003). Theoretically, when there is a match between strengths and opportunities and a competitive advantage is developed, performance should be maximized. However, although research regarding strategy in the hospitality industry is grounded in the historical perspective of strategic management as an essentially rational process, in reality, the process is much more complex (Olsen \& Roper, 1998).

Although rational models of strategic management describe a set of cognitive activities that include problem identification, alternative generation, evaluation, and choice (Simon, 1965); incremental models portray the process in more behavioral terms (Quinn, 1980). According to incrementalism, decisions are often made in response to environmental forces, and strategy may result from autonomous initiatives at various levels of the organization (Burgelman, 1983). Although actions are selected that satisfy a specific remedial need, such actions can usually be rationalized to fit top management's concept of organizational strategy (Narayanan \& Fahey, 1982).

How does strategy develop in organizations in which no comprehensive study of the environment or study of internal strengths and weaknesses is undertaken? One answer is that strategies emerge from the day-to-day decision making that takes place. Although documented strategic plans may be developed by simply describing the strategy that emerges, there are cases in which strategic plans are developed in a deliberate fashion, despite management not undertaking any comprehensive study. We believe that the concept of macroculture may be useful to explain how deliberate strategies are developed when certain specific data regarding a hotel's internal and/or external environment are not available. 


\section{THEORY DEVELOPMENT}

In brief, macroculture is manifested in consistency in strategies, processes, and operations among organizations operating in the same industry (Abrahamson \& Fombrun, 1994). It is rooted in beliefs, norms, and mental models shared by numerous organizational members in an industry. These common strategies, processes, and operations may or may not be functional from the perspective of any single organization. Functionality, in this case, means that the management of the organization scans the environment and adapts in a manner congruent with environmental threats and opportunities, regardless of how difficult or painful such adaptation may be. Dysfunctional organizational behavior, on the other hand, results in management not consistently reacting in a manner congruent with environmental pressures, and in doing so, expected results are not achieved. There is evidence that organizations often adopt strategies despite mixed evidence about the strategy's performance, and the existence of evidence that the strategy results in inefficient outcomes (O’Neill, Pouder, \& Buchholtz, 1998). Such organizational behavior has been previously explained by the degree of bargaining, solicitation, and political activity associated with the strategic decision making (Johnson, 1988).

Research into the role that industry macroculture plays in strategic decision making is in its infancy and has largely been conceptual. Research on this topic is generally considered to have begun when Abrahamson and Fombrun (1994) reported on the American automobile industry. As consumer tastes and desires regarding automobiles gradually changed in the 1960s and 1970s, Japanese automobile manufacturers began to cater to these changing demands. At the same time, however, the Big Three American automobile manufacturers continued to produce products consistent with consumer tastes of the 1950s. American automobile manufacturers were supported in their endeavor to manipulate consumer tastes (apparently unsuccessfully) by other parties with which they did business, such as vendors, as well as by the other major U.S. car makers, thus forming a macroculture (Abrahamson \& Fombrun, 1994). Managers of automobile manufacturers, who employed many of the same consultants, read the same professional journals, attended the same professional conferences, and belonged to the same associations, reinforced the macroculture. Needless to say, following this period of myopia, American automakers were catching up with the Japanese manufacturers in terms of product development for years to come.

Likewise, the American lodging industry presents a potential case study in such behavior. Prior to the recession in the early 1990s, great optimism prevailed in the American lodging industry regarding the viability of limited-service, economy-priced hotels, such as the Days Inn concept (Dahl \& Carlton, 1990). Lodging company executives introduced a large number of new economy hotel brands, and eventually many of these organizations filed for Chapter Eleven bankruptcy protection. As a result, many of the economy hotels that were constructed during this period of optimism were financial disasters (Dahl \& Carlton, 1990). In more recent years, similar optimism overtook the American lodging industry regarding the viability of all-suite hotels. Throughout the early to mid 1990s, the demand by 
consumers for all-suite hotel rooms increased at an average rate of approximately 15 percent per year (Ross, 1996), fueling this optimism. However, in the late 1990s, the demand for all-suite hotel rooms had increased less than 5\% per year, and concomitantly, this period included one of the sharpest rebounds in the lodging industry's history (O'Neill, 2000). This paradoxical relationship is further highlighted by the fact that during 1996, the average daily vacancy of all-suite hotels actually increased by $17 \%$, and yet 14 new all-suite hotel brands were announced during the same year, mostly by existing major hotel chains (O'Neill, 1997). Thus, to some extent, these data provide initial evidence that a macroculture may exist in the lodging industry because it appears that strategic models may proliferate like fashions leading to overbuilding. In other words, many lodging organizations and their executives may be imitators rather than prospectors, indicating that these organizations are not effectively managed from a strategic standpoint.

Macroculture in the lodging industry may be nurtured because of the increasing complexity of environmental information managers must address. The development of an organization's strategy requires managers to analyze a large number of environmental factors. However, decision makers are limited in their ability to make such comparisons by cognitive constraints, or bounded rationality (Simon, 1957, 1976). Furthermore, managers may be unable to predict the effect of the environment on one's own firm (i.e., organization effect) and/or unable to predict the consequences of a particular strategic decision (i.e., decision response). Miller and Shamsie (1999) suggest that organization effect and decision response will discourage strategic variation. There is evidence that managers, faced with complex information-processing tasks such as strategy development, will use a variety of heuristics to simplify information processing (Cyert \& March, 1963, 1992; Kahneman \& Miller, 1986). Mental models may be culturally influenced heuristics providing managers normative information that allows them to process complex information.

Macrocultural theory brings the level of analysis of culture from a single organization to multiple organizations that are somehow interrelated. Pfeffer (1981) saw organizational culture as symbolic or expressive management that uses a system of shared meanings and beliefs to result in a socially constructed reality. More recently, Robert and Wasti (2002) have viewed organizational culture at the societal level. From this starting point, macroculture may be viewed as a macro force that spans numerous organizations in a social system (e.g., the hotel industry), many or all of which may be in competition with one another. Abrahamson and Fombrun (1994) focused on macroculture as shared beliefs when they identified macroculture as beliefs that are shared by managers across organizations that tend to increase the level of organizational inertia and similarity while decreasing inventiveness. Love, Priem, and Lumpkin (2002) suggest that the level of organizational inertia may actually be compounded when executives explicitly articulate the organization's strategy to organization members. For the purpose of this article, macroculture is defined as: Organizational culture manifested in behavior patterns shared among organizational participants in an industry resulting from 
shared beliefs, needs, and/or circumstances, and resulting in similar mental models, similar perceptions of strategic issues, and similar strategies.

To operationalize the concept of mental models, we have developed the term Strategic Issue Perception (SIP). A SIP is simply a manager's perception of the issues that will affect the organization's long-term success. Such mental models, or cognitive schema, may be developed either directly from one's experiences, or indirectly by being passed along by members of a reference group or culture (Sims \& Lorenzi, 1992). It is this indirect method of schema or mental model development in which we are interested.

In developing hypotheses, we asked the question: What are the boundaries of a macroculture, and how are these boundaries determined? One option for establishing boundaries is analyzing organizations for common operating characteristics, markets, or technologies. In addition to placing boundaries around a group of organizations based on these factors, Porac and Thomas (1990) proposed a subjective definition that relies on categories defined by managers themselves. Essentially, they defined a competitive set as a group of organizations that perceive themselves as distinct and similar to one another while simultaneously being different to those outside of the category (Porac \& Thomas, 1990). Factors hotel managers might use to distinguish themselves as being a member of a competitive set may include size, price level, style of operation, and/or level of services offered. For the subject study, competitive sets that were analyzed included full service and limited service hotels based on our discussions with lodging managers and our research of the lodging industry. These two sets are of a similar size and a sufficient number of respondents per set in the subject study. Furthermore, support already exists for hotels being categorized in such a manner (O'Neill, 1997). Generally, lodging managers consider full-service hotels to include a complement of restaurants, lounges, banquet operations, and other services, whereas limited-service hotels are not considered to include such amenities and services. However, some properties offer limited food, beverage, and other services, and therefore, may not be so neatly categorized. Thus, in our study, we ultimately categorized hotels based on managers telling us whether they considered themselves to be operating full- or limited-service hotels, consistent with the approach suggested by Porac and Thomas (1990). We would therefore expect that any macrocultural tendencies would be most acute within competitive sets. In our study, we found that the competitive sets possessed significant differences on the basis of number of guest rooms, number of diamonds awarded by AAA, occupancy rate, and average daily rate, indicating that several variables may be taken into account when hotel managers position their properties as either limited or full service. Details regarding these variables are provided later in this article.

In rational models of strategy, top managers should evaluate key external forces affecting the organization, including social, cultural, demographic, economic, and legal forces (e.g., David, 2003). These key external forces affect customers, communities, markets, and other stakeholders (Wheelen \& Hunger, 2002). The evaluation of customer demand may be one of the most important aspects of managers' rational environmental scanning in the hospitality industry. Therefore, we would expect that any influence of a macroculture on a manager's 
SIPs should be above and beyond the perceived influence of customer (guest) demands.

\section{The Development of a Macroculture}

Simons and Namasivayam (1999) conceptually posited that such factors as professional journals, associations, and conferences lodging executives read, belong to, and attend should be included as predictor variables in an analysis of lodging industry executive perceptions of threats and opportunities. Thus, we analyze whether the macroculture includes these factors of journals, associations, and conferences. This position is grounded in institutional theory, the perspective of which is that the firm is constrained by the institutions that prescribe industrial values and norms (e.g., Zucker, 1987). This perspective includes the evaluation of the role of institutional scripts and schema (Greenwood \& Hinings, 1996), which exist as mental models. Our study analyzes these factors because we believe that they may serve as the sources and reinforcers of mental models in the hospitality industry. We believe that any influence of these factors on managers' SIPs is above and beyond the effect of managers rationally analyzing customer (guest) demand, as previously stated. In addition, we examine the effect of these macrocultural forces within manager-defined competitive sets (i.e., full-service and limited-service hotels), because as previously stated, the literature suggests that the effects of macrocultural forces may be most acute within competitive sets. Stated alternatively:

Hypothesis 1a: The greater the degree to which managers read the same professional journals, the more likely they rate SIPs similarly.

Hypothesis $1 b$ : The greater the degree to which managers in competitive sets read the same professional journals, the more likely they rate SIPs similarly.

Hypothesis 2a: The greater the degree to which managers participate in the same associations, the more likely they rate SIPs similarly.

Hypothesis $2 b$ : The greater the degree to which managers in competitive sets participate in the same associations, the more likely they rate SIPs similarly.

Hypothesis $3 a$ : The greater the degree to which managers attend the same professional conferences, the more likely they rate SIPs similarly.

Hypothesis $3 b$ : The greater the degree to which managers in competitive sets attend the same professional conferences, the more likely they rate SIPs similarly.

Haveman (1993) found empirical support for the theory that managers in competitive organizations will, over time, begin to imitate strategic actions related to organizational growth and entry into new markets. Haveman (1993) referred to this tendency for competing organizations to become increasingly similar over time as mimetic isomorphism. The subject study makes the final hypotheses that as management employees transfer from one competitive hotel to another, the macroculture is cultivated, and more common SIPs develop among managers. Stated alternatively:

Hypothesis 4a: Hotel managers who have been previously employed by a greater number of competitive hotels will be more likely to rate SIPs similarly. 
Hypothesis 4b: Hotel managers in competitive sets who have been previously employed by a greater number of competitive hotels will be more likely to rate SIPs similarly.

\section{METHOD}

\section{Sample, Respondents, and Procedures}

The research methods employed in this study follow recommendations developed by Okumus (2002), namely that strategic management research in the hospitality industry be implemented through collaboration with leading commercial hospitality organizations and with well-established business schools. The research design for this study involved questionnaires that surveyed hotel general managers and hotel owners/executives. We first administered an open-ended questionnaire as a preliminary pilot study to develop measures for the study survey and distributed it to an initial 378 participants. The primary purpose of the pilot study was to gather information regarding strategic issues, professional journals, associations, and conferences from managers in the lodging industry rather than merely imposing a researcher-specified framework on them in our final surveys. The final surveys were distributed to approximately 1,900 managers and executives in a variety of geographic locations around the world, but primarily in North America. One questionnaire was distributed to general managers, and another similar, but less comprehensive questionnaire was sent to hotel owners and executives, although all survey items encompassing pooled data were identical in the two surveys. Furthermore, factor analyses revealed that in each case, there were an equal number of underlying factors (to be discussed in greater depth later in this article) and the items loading on each relevant factor were identical for each of the two groups of respondents.

Each potential participant received an initial mailing that included a letter explaining the forthcoming survey but not including the survey itself. The longer, more comprehensive questionnaire was mailed to approximately 1,000 randomly selected hotel general manager members of the American Hotel \& Lodging Association (AH\&LA). Most of these general managers were stationed in the United States although because the sample of 1,000 addressees was randomly selected from the AH\&LA's database, a small number of general managers employed by U.S.-based lodging concerns, but stationed outside of the United States, were included. An analysis of the survey responses of U.S.-based versus non-U.S.based participants indicated that the responses of these two groups were not systematically different (i.e., there were no significant differences in the SIPs of the two groups). Only one manager (typically the most senior manager) was surveyed at each randomly selected hotel property. The hotel general manager sample represented a variety of geographical areas and hotel location types (e.g., downtown, highway, airport, suburban, and resort). The shorter, less comprehensive questionnaire was mailed to approximately 900 owners and executives of hotel companies. Their names and addresses were gathered from databases provided by the consulting firm, HVS International (approximately 600 addressees) and the Asian-American Hotel Owners Association, or AAHOA (approximately 300 
addressees). Members of AAHOA are estimated to own approximately one third of North American hotels (Higley, 2002). Both the presidents of the AH\&LA, and the American Hotel \& Lodging Foundation (AH\&LF), the research arm of the AH\&LA, and the provider of a grant for this study, signed the initial letters to managers and executives, as well as the cover letters accompanying the questionnaires. Finally, to maximize the response rate, a follow-up questionnaire was mailed to those managers and executives not responding to the first mailing.

A total of 331 responses were received, representing an overall response rate of approximately $17 \%$. The 331 total responses included 142 owners/executives and 189 general managers, for response rates of approximately 16 percent among owners/executives and 19 percent among general managers. Although the response rates may appear to be low, it is important to remember that the hospitality industry is well known as a seven-day-per-week business where managers work long hours, leaving them with limited time for other activities, so these apparently low response rates are not unusual for research involving hotel industry executives. For example, a survey of its own members (hotel owners and managers) conducted by AAHOA resulted in a response rate of only 9\% (Raio, 1999), and a hospitality industry survey of executives conducted by New York University yielded a response rate of only $8 \%$ (Walsh, 2000). Furthermore, there do not appear to be any systematic differences between the respondents and nonrespondents. For example, respondents are representative of the same geographic regions and hotel chains represented by the nonrespondents, and the response rates for each group are comparable. In addition, based on the information presented in Table 1, the characteristics of the respondents' hotel properties appear to be reflective of industry averages.

\section{MEASURES}

Competitive sets. As previously discussed, in addition to analyzing the entire sample, we analyzed the data by limited-service and full-service competitive sets based on our discussions with lodging managers and previous research ( $\mathrm{O}^{\prime} \mathrm{Neill}$, 1997). We found that the competitive sets possessed significant differences on the bases of number of guest rooms $(t=-6.83, p<.001)$, number of diamonds awarded by AAA $(t=-2.78, p<.01)$, annual occupancy percentage rate $(t=$ $-2.50, p<.01)$, and annual average daily rate, or $\operatorname{ADR}(t=-5.99, p<.001)$. The means for each of the relevant variables that we measured in each competitive set are presented in Table 1.

Likert scales. Respondents provided summated ratings based on Likert scales ranging from low to high on each given characteristic (e.g., "How important is each issue to your organization?" or "Rate your frequency of participation."). We believe the power of the data is justified, and furthermore, although such data could be considered to be ranked (ordinal) data because there was an underlying continuous distribution, we believe it to be closer to interval-level data because, based on the survey design, we applied Likert scales in an appropriate manner and consistent with recommendations of seminal research on this topic (Rosenthal \& 
Table 1

Characteristics of Hotel Properties

\begin{tabular}{lrccc}
\hline Statistic & Rooms & Diamonds $^{\mathrm{a}}$ & Occupancy $^{\mathrm{b}}(\%)$ & $\begin{array}{c}\text { Average Daily } \\
\text { Rate }(\$)\end{array}$ \\
\hline Mean $(n=188)$ & 137.83 & 2.21 & 67.54 & 88.28 \\
SD & 144.02 & 1.91 & 12.91 & 59.77 \\
Minimum & 14.00 & 0.00 & 25.00 & 30.00 \\
Maximum & 950.00 & 5.00 & 96.00 & 395.00 \\
Competitive set means: & & & & \\
$\quad$ Limited service $(n=86)$ & 67.83 & 1.91 & 64.80 & 60.83 \\
Full service $(n=103)$ & 196.85 & 2.46 & 69.67 & 110.60 \\
\hline
\end{tabular}

a. As awarded by the American Automobile Association (AAA); 5 diamonds represents highest quality.

b. Numbers represent annual figures for the most recent fiscal year.

Rosnow, 1991). Furthermore, because the distributions of responses appear to be relatively normal, we feel justified in treating the responses as interval-level data.

SIPs. In the preliminary pilot study, 378 managers provided information regarding their opinions of the most important strategic issues facing the lodging industry. These questions were open-ended, and therefore, managers' perceptions of SIPs were based on their own perceptions of their operating environment and their own definitions of strategic issues (i.e., not necessarily a particular "academic" definition). Results were content-analyzed by two trained graduate students. Training consisted of the principal investigators providing to the graduate students an orientation regarding the intent and goals of the research, reviewing the first several returned surveys with the graduate students, and then periodically reviewing with the graduate students their interpretations of responses. Based on that analysis, we identified 20 basic strategic issues. The survey for the present study listed these 20 strategic issues and requested that all respondents rate the importance of each strategic issue to their business on a scale of 1 to 5 . We conducted a maximum-likelihood factor analysis of these results to reduce the list of 20 variables into a more parsimonious set to allow simpler description and discussion of the strategic issues of importance to managers. To allow for the easiest possible interpretation of the results, the data were rotated using Equamax Rotation with Kaiser Normalization. Based on an analysis of a scree plot, three underlying factors resulted, all of which had eigenvalues in excess of $1.0(5.47,2.45$, and 1.28 for factors 1,2 , and 3 , respectively), indicating strong support for three fundamental underlying factors among the 20 strategic issues identified on the final questionnaires.

Based on an analysis of the 20 strategic issues, 16 of the strategic issues clearly loaded on one of the three identified factors (four strategic issues were dropped from subsequent analyses). Six items loaded on factor 1, which includes such strategic issues as improving guest service, building customer relationships, and training employees, and will be hereafter referred to as "Service" strategic issues. 
Table 2

Factor Loadings of Strategic Issues

\begin{tabular}{llrl}
\hline Strategic Issue & Service & Growth & Property \\
\hline Improving guest service & $\mathbf{0 . 6 5 2}$ & -0.053 & 0.269 \\
Building customer relationships & $\mathbf{0 . 4 9 3}$ & 0.051 & 0.394 \\
Hiring qualified people & $\mathbf{0 . 7 8 6}$ & -0.015 & 0.070 \\
Training employees & $\mathbf{0 . 8 4 4}$ & 0.067 & 0.153 \\
Motivating employees & $\mathbf{0 . 7 1 2}$ & 0.129 & 0.089 \\
Protecting the environment & $\mathbf{0 . 4 1 6}$ & 0.146 & 0.321 \\
Financing expansion & 0.024 & $\mathbf{0 . 4 5 9}$ & 0.217 \\
Working with franchisors & 0.021 & $\mathbf{0 . 3 6 7}$ & 0.356 \\
REITs buying/selling hotels & 0.032 & $\mathbf{0 . 7 6 2}$ & 0.047 \\
Merger mania & 0.033 & $\mathbf{0 . 6 6 4}$ & 0.176 \\
International expansion & 0.091 & $\mathbf{0 . 4 6 8}$ & 0.278 \\
Renovating facilities & 0.329 & 0.147 & $\mathbf{0 . 3 6 1}$ \\
Implementing technological advances & 0.211 & 0.203 & $\mathbf{0 . 5 3 6}$ \\
Selling on the Internet & 0.308 & 0.139 & $\mathbf{0 . 3 3 3}$ \\
Growth in brand names & 0.046 & 0.297 & $\mathbf{0 . 4 4 3}$ \\
Branding of food and beverage outlets & 0.145 & 0.213 & $\mathbf{0 . 3 3 5}$ \\
\hline
\end{tabular}

Note: Boldfaced numbers represent factor loadings of strategic issues. REITs = real estate investment trusts.

Service strategic issues accounted for 28.7 percent of the variance in the items. Four items loaded on factor 2, which includes such strategic issues as financing expansion, international expansion, and real estate investment trusts (REITs) buying/selling hotels, and will be hereafter referred to as "Growth" strategic issues, and this factor accounted for $14.7 \%$ of the variance. Six items loaded on factor 3, which includes such strategic issues as renovating facilities, implementing technological advances, and branding of food and beverage outlets, and will hereafter be referred to as "Property" (asset) strategic issues," and this factor accounted for $6.5 \%$ of the variance. Table 2 summarizes the factor loadings of the strategic issues.

A reliability analysis using Cronbach's alpha (Cronbach \& Quirk, 1971) was conducted for each of the three identified factors, with the alphas for the service factor being .83, for growth being .75, and for property issues being .70 .

Each respondent was given a score for each of the three underlying factors (service, growth, and property), which was the mean of the respondent's rating for each of the strategic issues loading on that factor. These three factors served as the response variables measuring SIPs.

Perceptions of customer importance. Perceptions of customer importance represent a surrogate for rational strategy. All respondents were asked to list their top five customer accounts, and to rate each account on a scale of 1 to 5, based on the overall importance of the account to the business at the subject hotel. Trained graduate students categorized each respondent's answers into one of 20 total possible categories, which were largely based on U.S. government standard industrial classification (SIC) codes and other customer categories that became evident 
in the course of the students' analysis. Training consisted of the principal investigators providing to the graduate students an orientation regarding the intent and goals of the research, reviewing SICs with the graduate students, reviewing the first several returned surveys with the graduate students, and then periodically reviewing with the graduate students their interpretations of responses. An analysis of frequencies revealed that the top five overall responses among the 331 respondents were (in order of frequency): commercial transients, manufacturing firms, leisure transients, groups and conventions, and high technology firms.

For each of five customer responses, each respondent was given a "customer score" of 0 to 5 , where 0 indicated that the respondent did not list one of the top five customer responses, and 5 indicated the respondent listed one of the top five responses and rated that customer as a "5" (i.e., highly important) in overall importance to the business. In other words, each respondent received a customer score for each customer response, which was the product of the factor of 1 (or 0 if the response was not one of the top five overall responses) multiplied by an "importance score" of 1 to 5 , as rated by the respondent. The sum of the five responses for each respondent became the "customer" variable, and this score ranged from 0 to 25 for each respondent (i.e., a score of 0 indicated low similarity of customers because none of the five identified customer groups were listed as the hotel's five top customers, whereas a score of 25 indicated high similarity of customers because all five identified customer groups were listed as the top five and were rated as highly important). This variable had a mean of 6.04 and a standard deviation of 6.43 .

Professional journals. Using the 16 professional journals and magazines (identified in the preliminary pilot study), respondents in the subject study were asked to rate frequency of reading on a scale of 1 to 5 . A maximum-likelihood factor analysis with equamax rotation was conducted to reduce the data to a more manageable number of factors. Four underlying factors resulted in eigenvalues in excess of $1.0(4.15,2.33,1.68$, and 1.21 for factors $1,2,3$, and 4 , respectively), indicating strong support for four fundamental underlying factors among the 16 publications listed on the questionnaire.

Based on an analysis of the 16 publications, 15 of the publications clearly loaded on one of the four factors (one publication was dropped from subsequent analyses). Factor 1, which includes such publications as Hotel \& Motel Management, Hotel Business, and Lodging, will be hereafter referred to as "Lodging News" publications. Lodging News publications accounted for $25.9 \%$ of the variance in the items (alpha $=.82$ ). Factor 2, which includes such publications as Business Week, Fortune, and Forbes, will be hereafter referred to as "News" (generic) publications, and this factor accounted for $14.6 \%$ of the variance (alpha $=.81$ ). Factor 3, which includes Nation's Restaurant News and Restaurant Hospitality, will hereafter be referred to as "Food \& Beverage" publications, and this factor accounted for $10.5 \%$ of the variance (alpha $=.70$ ). Factor 4 , which includes the Journal of Hospitality \& Tourism Research and Cornell Quarterly, will hereafter be referred to as "Academic" publications, and this factor accounted for $7.5 \%$ of the variance $($ alpha $=.60)$. Although the coefficient alpha for academic publica- 
tions is relatively low, it was retained because of the exploratory nature of this work and because of the practical ramifications of the two academic publications mathematically loading on a single factor.

Professional associations. Using the nine professional associations (identified in the pilot study), respondents in the subject study were asked to rate level of participation on a scale of 1 to 5 , with 5 being the highest level of participation. A maximum likelihood factor analysis with equamax rotation was conducted to reduce the nine variables to a manageable number of factors. However, the nine professional associations did not load on a smaller number of factors that resulted in any practical meaning, so we combined the professional associations into one composite variable. A reliability analysis was conducted for the associations as a single factor, resulting in an alpha of .75 .

Professional conferences. Using the 10 professional conferences (identified in the pilot study), respondents in the subject study were asked to rate frequency of attending on a scale of 1 to $5(1=$ never attend and $5=$ always attend $)$. Maximum likelihood factor analysis with equamax rotation was conducted using the 10 professional conferences and three factors were derived, each with eigenvalues in excess of 1.0 (3.00, 1.37, and 1.17 for factors 1, 2, and 3, respectively). Eight of the conferences clearly loaded on one of the three factors (two conferences were dropped from subsequent analyses). Factor 1, accounting for $30 \%$ of the variance in the items, which includes such conferences as the New York University Hospitality Investment Conference and the University of California at Los Angeles Hospitality Investment Conference, will be hereafter referred to as "Investment" conferences (alpha $=.73$ ). Factor 2, which includes the AHLA Annual Convention \& Leadership Forum and the International Hotel/Motel \& Restaurant Show (sponsored by the AHLA), will be hereafter referred to as "AHLA" conferences, and this factor accounted for $13.7 \%$ of the variance (alpha $=.60$ ). Factor 3 , which includes the Hospitality Sales \& Marketing Association International Annual Convention and the Council on Hotel, Restaurant, and Institutional Education Annual Conference, will hereafter be referred to as "Other" conferences, and this factor accounted for $10.8 \%$ of the variance $($ alpha $=.48)$. Because the three conferences making up the other factor were unrelated from a practical standpoint and the alpha was very low, this factor was omitted from subsequent analyses.

Previous employment. Previous employment, or "Employment," is simply a measure of the number of competitive hotels where the responding hotel general manager had been previously employed, (i.e., not merely other hotels, but other competitive hotels). General managers were asked to first list their primary competitors, and subsequently were asked for the number of these competitive hotels where they were previously employed. The question regarding previous employment in competitive hotels appeared only on the questionnaire for hotel general managers, because they operate a single hotel property within a definable competitive set (a set that was identified by the general managers themselves on the questionnaires). On the other hand, corporate executives or owners typically have responsibility for numerous properties. Therefore, hotel general managers, not 
Table 3

Demographics of Survey Respondents

\begin{tabular}{lcrrrr}
\hline Variable & $n$ & Mean & $S D$ & Minimum & Maximum \\
\hline Age & 331 & 46.4 & 10.9 & 23 & 78 \\
Years in this industry $^{\text {Years at this hotel }}{ }^{\mathrm{a}}$ & 331 & 19.5 & 10.4 & 0 & 60 \\
Years in this position $^{\mathrm{a}}$ & 189 & 6.9 & 8.3 & 0 & 41 \\
Year $^{2}$ & 189 & 5.6 & 6.6 & 0 & 41 \\
\hline
\end{tabular}

a. These questions appeared only on the survey of hotel general managers.

executives, may be queried regarding their previous employment in hotels within their competitive set.

Demographic and organizational variables. Manager age, gender, education levels, years in current position, and years in the hospitality industry were measured. The mean respondent age was 46.35 years old $(n=331)$. The mean number of years for general managers in their current position was 5.57 years. The mean number of years involved in the hospitality industry was 19.54 years (17.27 years for general managers, 23.14 years for owners/executives). Approximately $76.5 \%$ of the respondents were men (68.8\% among general managers, $88.5 \%$ among owners/executives) and $23.5 \%$ were women (31.2\% among general managers, $11.5 \%$ among owners/executives). Approximately $42.6 \%$ of the respondents reported having college degrees, and $57.4 \%$ did not.

Hotel general managers and executives were asked to provide certain other information about themselves and their hotel properties. That information is summarized in Tables 3 and 4.

Analysis. The data were analyzed using hierarchical regression analysis. Previous research on organizational strategy has found hierarchical regression analysis to be an effective analytical tool (e.g., Dooley et al., 2000). For each hypothesis, each of the three SIPs was regressed on perceptions of customer importance in Step 1, and then in Step 2, the specific, hypothesized macrocultural source (i.e., professional journals, associations, conferences, and previous employment) was added to the regression. These analyses were conducted regarding the data from the total sample of managers, and also regarding the data from managers within each competitive set (i.e., full-service and limited-service hoteliers). Standardized beta coefficients are summarized in Table 5 .

\section{RESULTS}

Hypothesis 1a proposes that the greater the degree to which managers read the same professional journals, the more likely they share SIPs. As previously stated, we tested the effects of journals on SIPs above and beyond any effects of perceptions of customer importance on SIPs. Perceptions of customer importance were found to be significantly related to service SIPs $\left(R^{2}=.03, F=10.58, p<.001\right)$, but after accounting for this variable in the hierarchical regression, journals were not 
Table 4

Frequencies of Hotel Property Variables

\begin{tabular}{|c|c|c|}
\hline Variable & Frequency & Percentage \\
\hline \multicolumn{3}{|l|}{ Style } \\
\hline All suite & 13 & 6.9 \\
\hline Not all suite & $\underline{176}$ & $\underline{93.1}$ \\
\hline Total & $\underline{189}$ & $\underline{100.0}$ \\
\hline \multicolumn{3}{|l|}{ Service } \\
\hline Full service & 103 & 54.5 \\
\hline Limited service & $\underline{86}$ & $\underline{45.5}$ \\
\hline Total & 189 & 100.0 \\
\hline \multicolumn{3}{|l|}{ Diamonds $^{a}$} \\
\hline 0 & 43 & 22.9 \\
\hline 1 & 5 & 2.7 \\
\hline 2 & 36 & 19.1 \\
\hline 3 & 82 & 43.6 \\
\hline 4 & 18 & 9.6 \\
\hline 5 & 4 & 2.1 \\
\hline Total & $\underline{18 \overline{8}}$ & $10 \overline{0.0}$ \\
\hline \multicolumn{3}{|l|}{ Ownership } \\
\hline Management company & 31 & 16.7 \\
\hline Insurance company & 1 & 0.5 \\
\hline Other company & 3 & 1.6 \\
\hline REIT & 6 & 3.2 \\
\hline Partnership & 36 & 19.4 \\
\hline Bank/financial & 1 & 0.5 \\
\hline Single owner & 101 & 54.3 \\
\hline Other owner & $\underline{7}$ & $\underline{3.8}$ \\
\hline Total & $18 \overline{6}$ & 100.0 \\
\hline \multicolumn{3}{|l|}{ Location } \\
\hline City & 62 & 32.8 \\
\hline Airport & 10 & 5.3 \\
\hline Highway & 45 & 23.8 \\
\hline Suburban & 43 & 22.8 \\
\hline Resort & $\underline{29}$ & $15.3 \%$ \\
\hline Total & $\underline{189}$ & $100.0 \%$ \\
\hline
\end{tabular}

a. As awarded by the American Automobile Association (AAA); 5 diamonds represents highest quality.

significantly related to service SIPs. We found that perceptions of customer importance were not significantly related to growth SIPs. However, after accounting for perceptions of customer importance in the hierarchical regression, journals were positively related to growth $\operatorname{SIPs}\left(\Delta R^{2}=.09, \Delta F=7.41, p<.001\right)$. In particular, lodging news publications had a standardized beta coefficient of $0.20(p<$ $.01)$, and news publications had a standardized beta coefficient of $0.13(p<.01)$. Neither perceptions of customer importance nor journals were significantly related to property SIPs. Therefore, Hypothesis 1a was only partially supported and we note the analyses yielded relatively low effect sizes. On the other hand, it is important for us to highlight that because we were measuring $\Delta R^{2}$ (as opposed to $R^{2}$ ) after the effect of customers was taken into account, relatively low effect sizes 
Table 5

Standardized Beta Coefficients Hierarchical Regression Analyses with Service, Growth, and Property Strategic Issues

\begin{tabular}{|c|c|c|c|}
\hline \multirow[b]{2}{*}{ Predictors } & \multicolumn{3}{|c|}{ Strategic Issues } \\
\hline & Service & Growth & Property \\
\hline \multicolumn{4}{|l|}{ Step 1} \\
\hline Customers & $0.18^{\star \star}$ & -0.02 & 0.04 \\
\hline \multicolumn{4}{|l|}{ Step 2} \\
\hline \multicolumn{4}{|l|}{ Professional journals and magazines } \\
\hline \multicolumn{4}{|l|}{ Overall $(\mathrm{H} 1 \mathrm{a})$} \\
\hline Lodging news magazines & 0.02 & $0.20^{* * *}$ & 0.10 \\
\hline News magazines & 0.03 & $0.13^{\star * *}$ & 0.01 \\
\hline Food magazines & 0.09 & -0.05 & -0.06 \\
\hline Academic journals & 0.05 & 0.11 & 0.09 \\
\hline \multicolumn{4}{|l|}{ Full service competitive set (H1b) } \\
\hline Lodging news magazines & 0.07 & $0.18^{*}$ & 0.08 \\
\hline News magazines & -0.03 & 0.05 & -0.12 \\
\hline Food magazines & 0.10 & 0.02 & 0.04 \\
\hline Academic journals & 0.04 & -0.02 & 0.12 \\
\hline \multicolumn{4}{|l|}{ Limited service competitive set $(\mathrm{H} 1 \mathrm{~b})$} \\
\hline Lodging news magazines & 0.12 & $0.27^{* *}$ & $0.31^{\star *}$ \\
\hline News magazines & 0.03 & -0.03 & $-0.26^{\star \star}$ \\
\hline Food magazines & -0.02 & 0.13 & 0.01 \\
\hline Academic journals & $0.21^{*}$ & 0.13 & $0.29^{* *}$ \\
\hline \multicolumn{4}{|l|}{ Professional associations } \\
\hline Overall $(\mathrm{H} 2 \mathrm{a})$ & $0.17^{\star \star \star}$ & $0.18^{* * *}$ & $0.15^{\star \star *}$ \\
\hline Full service competitive set (H2b) & $0.20^{\star *}$ & $0.21^{\star *}$ & 0.14 \\
\hline Limited service competitive set (H2b) & $0.20^{*}$ & $0.26^{\star *}$ & $0.21^{\star *}$ \\
\hline \multicolumn{4}{|l|}{ Professional conferences } \\
\hline \multicolumn{4}{|l|}{ Overall $(\mathrm{H} 3 \mathrm{a})$} \\
\hline Investment conferences & $-0.20^{\star * *}$ & $0.32^{\star * *}$ & 0.10 \\
\hline AH\&LA conferences & 0.07 & 0.00 & -0.01 \\
\hline \multicolumn{4}{|l|}{ Full service competitive set (H3b) } \\
\hline Investment conferences & 0.01 & 0.11 & -0.12 \\
\hline AH\&LA conferences & -0.07 & 0.01 & -0.07 \\
\hline \multicolumn{4}{|l|}{ Limited service competitive set (H3b) } \\
\hline Investment conferences & $-0.31^{\star \star *}$ & 0.10 & -0.17 \\
\hline AH\&LA conferences & -0.10 & 0.09 & 0.09 \\
\hline \multicolumn{4}{|l|}{ Previous employment } \\
\hline Overall $(\mathrm{H} 4 \mathrm{a})$ & -0.13 & $0.20^{* * *}$ & -0.02 \\
\hline Full service competitive set (H4b) & $-0.19+$ & 0.07 & -0.11 \\
\hline Limited service competitive set (H4b) & -0.06 & $-0.19^{\star *}$ & 0.10 \\
\hline
\end{tabular}

${ }^{*} p<.10 .{ }^{* *} p<.05 .{ }^{* *} p<.01$.

were not unexpected, particularly for the entire sample because previous conceptual research in the area of interorganizational macroculture suggested that effect sizes would be greatest within competitive sets (Porac \& Thomas, 1990), which is essentially what we found in this research.

Hypothesis $1 \mathrm{~b}$ proposes that the greater the degree to which managers in competitive sets read the same professional journals, the more likely they share SIPs. In regression analyses of the limited service competitive set, (in relation to jour- 
nals), the effect of journals on growth SIPs was significant, $\left(\Delta R^{2}=.16, \Delta F=3.54\right.$, $p<.01$ ), after accounting for perceptions of customer importance in the hierarchical multiple regression analysis. In particular, lodging news journals had a standardized beta coefficient of $0.27(p<.05)$. In addition, journals had a significant relationship to property $\operatorname{SIPs}\left(\Delta R^{2}=.19, \Delta F=4.57, p<.01\right)$. In particular, lodging news journals had a standardized beta coefficient of $0.31(p<.01)$, news journals had a standardized beta coefficient of $-0.26(p<.05)$, and academic journals had a standardized beta coefficient of $0.29(p<.05)$. No significant results were found in the analyses of the full-service competitive set. However, due to the significant relationships among lodging news, news, and academic publications and property strategic issues in the limited-service competitive set, Hypothesis $1 \mathrm{~b}$ was partially supported. It is important to note that the coefficient pertaining to the news variable was negative. In other words, managers reading generic news publications were more likely to believe that property-strategic issues were significantly less important.

Hypothesis 2 a proposes that the greater the degree to which managers participate in the same associations, the more likely they share SIPs. As previously stated, perceptions of customer importance were found to be significantly related to service SIPs. After accounting for the effect of customers, associations were significantly related to service SIPs $\left(\Delta R^{2}=.06, \Delta F=9.20, p<.01\right)$. Similarly, associations were significantly related to growth $\operatorname{SIPs}\left(\Delta R^{2}=.03, \Delta F=9.84, p<\right.$ $.01)$ and property SIPs $\left(\Delta R^{2}=.02, \Delta F=6.76, p<.01\right)$. Therefore Hypothesis $2 \mathrm{a}$ was supported, although we note the analyses yielded relatively low effect sizes, though these low effect sizes were not entirely unexpected, as previously discussed.

Hypothesis $2 \mathrm{~b}$ proposes that the greater the degree to which managers in competitive sets participate in the same associations, the more likely they share SIPs. In hierarchical regression analyses of the full-service competitive set, beyond the effect of perceptions of customer importance, associations were significantly related to service SIPs $\left(\Delta R^{2}=.16, \Delta F=16.93, p<.05\right)$ and growth SIPs $\left(\Delta R^{2}=\right.$ $.04, \Delta F=4.32, p<.05)$. Within the limited-service competitive set, associations were significantly related to growth SIPs above and beyond the customer effect $\left(\Delta R^{2}=.36, \Delta F=31.76, p<.01\right)$, as well as significantly related to property SIPs $\left(\Delta R^{2}=.22, \Delta F=19.16, p<.05\right)$. Therefore, Hypothesis $2 \mathrm{~b}$ was partially supported.

Hypothesis 3 a proposes that the greater the degree to which managers attend the same conferences, the more likely they share SIPs. In hierarchical regression analyses, conferences were significantly related to service SIPs after accounting for perceptions of customer importance $\left(\Delta R^{2}=.06, \Delta F=4.94, p<.01\right)$. In particular, investment conferences had a standardized beta coefficient of $-0.20(p<.01)$, indicating that attending investment conferences is negatively related to service SIP importance. In addition, after accounting for the customer effect, conferences were significantly related to growth $\operatorname{SIPs}\left(\Delta R^{2}=.10, \Delta F=17.59, p<.01\right)$. In particular, investment conferences had a standardized beta coefficient of $0.32(p<$ $.01)$, indicating a positive relationship between attending these conferences and 
growth-strategic perceptions. These findings provide partial support for Hypothesis 3a.

Hypothesis $3 \mathrm{~b}$ proposes that the greater the degree to which managers in competitive sets attend the same professional conferences, the more likely they share SIPs. With regard to the limited-service competitive set, attending conferences was significantly related to service SIPs after accounting for perceptions of customer importance $\left(\Delta R^{2}=.11, \Delta F=4.93, p<.01\right)$. In particular, investment conferences had a standardized beta coefficient of $-0.31(p<.01)$, indicating that attending such conferences is negatively related to service SIPs among managers of limited-service hotels. No significant results were found in the analyses of the full-service competitive set. Therefore, Hypothesis $3 \mathrm{~b}$ was partially supported.

Hypothesis $4 \mathrm{a}$ proposes that hotel managers who have been previously employed by a greater number of competitive hotels will be more likely to share SIPs. In the hierarchical regression analyses of the full sample of hotel managers, previous hotel employment was significantly related to growth SIPs $\left(\Delta R^{2}=.04\right.$, $\Delta F=7.54, p<.01$ ), after accounting for the managers' perceptions of customer importance. Therefore, Hypothesis 4 a was partially supported with respect to the growth strategy but not with respect to the service or property strategies.

Hypothesis $4 \mathrm{~b}$ proposes that hotel managers in competitive sets who have been previously employed by a greater number of competitive hotels will be more likely to share SIPs. Within the limited-service competitive set, previous hotel employment was significantly related to growth $\operatorname{SIPs}\left(\Delta R^{2}=.12, \Delta F=12.28, p<\right.$ .01 ), after accounting for the customer effect. No significant relationships were found between previous hotel employment and the service and property SIPs among managers in the limited service competitive set. Furthermore, no significant results were found in the analyses of the full-service competitive set among previous hotel employment and the SIPs. Therefore, Hypothesis $4 \mathrm{~b}$ was partially supported.

\section{Discussion}

This present study was conducted to understand links between sources of macroculture and managers' perceptions of the importance of various strategic issues in the hotel industry. The results indicate the existence of fundamental strategic issues of importance to lodging executives and managers. In particular, three fundamental mental models became evident in this research. One mental model is the "service" model that is characterized by a belief that building relationships with customers through effectively training and motivating employees is of strategic importance. The "growth" model is a belief that managing growth through acquiring financing and finding new markets in which to expand is of strategic importance. A third factor, the "property" (asset) mental model is a belief that maintaining and renovating the physical plant, as well as implementing new technology, is of strategic importance. We sought to better understand what sources of macroculture might link with these different mental models regarding the success factors (i.e., SIPs) in the lodging industry. 
The results of this study appear to indicate that managers at both the executive (corporate) and general manager (unit) levels in the lodging industry who have similar perceptions of customer type and importance have a strategic focus on service issues, which presumably these customers demand. After we made this discovery, we sought to measure the effect of the sources of macroculture, above and beyond the effect of perceptions of customer importance (as a surrogate for rational strategy), on managers' SIPs.

Among hotel general managers, it appears that reading certain professional journals, attending professional conferences, and activity in professional associations are partially correlated with those managers attaching similar levels of significance to fundamental mental models, including service, growth, and propertystrategic issues. Managers should be aware, for example, that the publications they read may promote institutional norms, thus influencing managers' SIPs. For example, this study revealed that managers who read lodging news magazines and general news magazines appear to be interested in growth strategies. On the other hand, if these managers wish to become more enlightened regarding service issues, they may not become so by reading the same lodging news magazines. Reading lodging and academic journals may help to focus these managers on property-strategic issues, whereas reading the general news magazines may result in these managers believing that property issues are less important. Therefore, similarity in strategic thinking may be partially related to the type of journals read by managers, above and beyond perceptions of customer demands. In our study, this conclusion is particularly true among managers who identified themselves as operators of limited-service hotels. Perhaps the hotel industry has expressed its concern regarding this apparent attention to growth over service among the management of limited-service hotels by the relatively recent renaming of this category of hotel type to "select service."

In the entire sample, which includes hotel owners and corporate executives as well as hotel general managers, there is evidence that activity in professional associations is partially related to those executives attaching similar levels of significance to fundamental strategic issues. For example, being a relatively active member of associations has a positive relationship with all of the strategic issues among the total sample, has a positive relationship to growth and property strategic issues in the limited-service hotels, and has a positive relationship in the fullservice hotels to service and growth issues. It is interesting to note that our hypotheses were relatively strongly supported with respect to professional association activity. Because high reported levels of activity in hotel-oriented professional associations is probably correlated with a high level of face-to-face contact with other hotel industry professionals, these results may indicate that face-toface communication with many of the same professionals over time may have a greater effect on the development of mental models and the dissemination of macroculture than non-face-to-face communication, such as professional journals and magazines.

Also, in the entire sample, attending investment-oriented conferences was partially correlated with perceived importance of growth strategic issues and negatively related to perceived importance of service strategic issues. Although one 
might expect managers who attend investment-related conferences to attach greater importance to growth issues, one might not expect these managers to consider service issues to be less important. We believe this finding provides possible evidence of the existence of a macroculture as a source of information about the external environment that may be incorporated into managers' thinking about the strategic focus of their firms. Because there is a general belief among many strategists that organizations cannot be "all things to all people" (David, 2003), we believe this finding may indicate that many hotel executives believe that establishing a strategic focus in one area necessitates minimizing the strategic focus in other areas.

This research appears to indicate that hotel general managers who have been previously employed by a greater number of competitive hotels than their peers may be more likely to attach strategic significance to growth issues. It is interesting to note that this result appears to be true of limited-service hotel managers.

These findings appear to be illustrative of processual approaches to strategy. Although processual approaches to strategy understand rational strategy making, they are also skeptical about rationality and believe that organizations are often sticky and messy and strategies emerge amid great confusion (Whittington, 2001). Models that explain processual approaches include the cognitive model and learning model.

The cognitive model of strategic decision making understands that decision making is not so much a rational process as an attempt by organizational executives to appear to be rational (Mintzberg, Ahlstrand, \& Lampel, 1998). Executives may tend to behave in this manner not because of lack of conviction or ethics but because of lack of time and because the world is so large and complex and human brains and their abilities to process information are very limited by comparison (Simon, 1976). As a result, the industry macroculture may provide to executives relatively simple, though not necessarily objective environmental interpretation.

Based on our research, hotel-executive strategic decision making may also be explained by the learning model, which introduces politics into the decision-making process, and the power school of thought, which views strategy formulation as an overt process of influence where powerful participants in the process of strategy formulation use politics to negotiate strategies that are beneficial to their own personal interests (Mintzberg et al., 1998). In other words, we are not suggesting that hotel executives are naïve in their development of strategic-issue perceptions, but that some may be calling upon strategic issues deduced by the macroculture because those particular issues are supportive of the executives' current interests. In summary, our research findings may confirm Olsen and Roper's (1998) proposition that in practice, strategic management in the hospitality industry is a very complex process, despite the fact that academic strategic-management literature related to the hospitality industry typically assumes a simpler, more rational process.

\section{Suggestions for Future Research}

Significant future research is possible in this area because, among other things, strategic-management research related to the hospitality industry is in the 
"embryonic state" (Okumus, 2002, page 109). Future research should investigate how management background (i.e., seasoning) results in certain managers apparently perceiving certain strategic issues to be more important to them than their peers with lesser management experience at competitive organizations. In particular, it would be interesting to investigate the degree to which personal career aspirations of managers and their mental models of the appropriate strategic direction of their firms are intertwined and perhaps jointly affected by macrocultural sources in an industry.

In addition, because this research focused on the hotel industry, future research should attempt to replicate these findings in other aspects of the hospitality industry, and in other industries. There appears to be colloquial evidence of strategic duplication in the restaurant business, for example, duplication of restaurant concepts.

\section{Limitations of the Research}

Limitations of this research include its reliance on a single, cross-sectional survey instrument that does not allow definitive determination of causality. In other words, the study does not allow us to know for certain whether mental models lead managers to read certain journals, belong to certain associations, or attend certain conferences, whether doing these activities leads one to think in a certain way, or whether the relationship is in fact bidirectional. Time series study designs that measure managerial exposure to macrocultural forces and strategic thinking and action at several points in time are necessary to better understand the causal direction of these relationships. Furthermore, although we attempted to isolate the functional effects of customers on SIPs, there are other potential predictor variables for which we have probably not accounted.

In addition, as mentioned earlier, the research yielded a relatively low response rate. However, the response rate is not necessarily low for hospitality industry research, and the characteristics of the respondents appear to be reflective of the characteristics of the nonrespondents.

Finally, some of our analyses resulted in relatively low effect sizes after we accounted for the effect of customers. In particular, the links between professional journals/associations and SIPs were relatively weak in the entire sample (i.e., there may be limited practical significance despite our finding of statistical significance). Typically, however, the effect sizes linking professional journals/associations and SIPs were greater in the samples of competitive sets as hypothesized by previous research.

\section{Managerial Implications}

Our results may indicate managers should be aware they could be influenced in their perceptions regarding actions appropriate for their own organizations based on their being aware of the actions of parties outside their own firms. Although these outside parties and actions may influence perceptions of strategies that are viable and functional for a given organization, they also may not be appropriate, as the lodging industry's previously discussed problems seem to indicate. The 
industry culture could be a powerful force that may cloud the thinking of not only the management of a single organization but most of the industry. The long-term effect on the industry may be disastrous. Managers should strive to examine environmental trends directly through empirical data, without relying, perhaps only semiconsciously, on conventional wisdom.

When managers think similarly in one context (e.g., SIPs), they may think similarly in other contexts as well (e.g., strategies). Managers need to strive to be aware of their biases, and aware that biases, which may not appear to be so because they are largely held throughout the industry, are probably related to many long-term strategic implications regarding organizational survival.

The concept of an industry macroculture may provide answers to managers regarding organizational stagnation. Actions taken by managers partially because they are acceptable based on cultural norms, may not be appropriate for a single given organization. O'Neill et al. (1998) suggested that organizations will often implement strategies despite a lack of evidence regarding the strategy's viability or performance, and in spite of evidence that the strategy leads to inefficient outcomes. Our research on macroculture provides a possible explanation regarding why such apparent dysfunction may occur, and partially supports the propositions developed by Abrahamson and Fombrun (1994).

Furthermore, cultural norms may be quite pervasive in the lodging industry. As a result, culture may be a force that managers, though aware of its existence, may believe they are able to do little to influence. However, assuming that professional journals, professional associations, and professional conferences are important aspects of the lodging industry culture, managers should be aware that they have the power to influence cultural sources. Managers may do so rather formally through writing to and for professional magazines and journals, participating in professional associations at high levels (for example, as an officer), and speaking at professional conferences. In addition, managers have the opportunity to influence industry culture through their informal interactions with members of the culture. In other words, managers in the lodging industry are not only likely to be a part of the industry culture, but are likely to have the potential to effect it. By affecting their culture, managers may be affecting their own organization's future viability and survival.

\section{CONCLUSION}

In conclusion, based on a factor analysis, we found there to be three fundamental strategic directions in U.S.-based lodging organizations. These three strategic directions, namely pertaining to service issues, growth issues, and property (asset) issues may be viewed as executive mental models of SIPs. Hotel industry executives appear, at least to some extent, to receive information about these SIPs from their membership in an industry macroculture. Based on subsequent factor analyses and hierarchical regression analyses, the results of the study indicate that professional journals, associations, conferences, and previous employment may be sources of the macroculture. The influences of and from the macroculture appear to be bidirectional, so although the macroculture may exert a powerful 
force on the perceptions of industry executives, executives may likewise influence the macroculture through their membership and activity in it.

\section{REFERENCES}

Abrahamson, E., \& Fombrun, C. J. (1994). Macrocultures: Determinants and consequences. Academy of Management Review, 19, 728-755.

Burgelman, R. A. (1983). Corporate entrepreneurship and strategic management: Insights from a process study. Management Science, 29, 1349-1364.

Cronbach, L. J., \& Quirk, T. J. (1971). Test validity. In L. C. Deighton (Ed.), Encyclopedia of education (vol. 9, pp. 165-175). New York: Macmillan.

Cyert, R. M., \& March, J. G. (1963). A behavioral theory of the firm. Engelwood Cliffs, NJ: Prentice-Hall.

Cyert, R. M., \& March, J. G. (1992). A behavioral theory of the firm (2nd ed.). Cambridge, MA: Blackwell.

Dahl, J., \& Carlton, J. (1990). Rooms to spare: Hotel industry suffers from a glut of capacity and faces big deficits. Wall Street Journal, 101, 1-7.

David, F. R. (2003). Strategic management concept (9th ed.). Upper Saddle River, NJ: Prentice Hall.

Dooley, R. S., Fryxell, G. E., \& Judge, W. Q. (2000). Belaboring the not-so-obvious: Consensus, commitment, and strategy implementation speed and success. Journal of Management, 26(6), 1237-1257.

Eisenhardt, K. M., \& Zbaracki, M. J. (1992). Strategic decision making. Strategic Management Journal, 13, 17-38.

Greenwood, R., \& Hinings, C. R. (1996). Understanding radical organizational change: Bringing together the old and the new institutionalism. Academy of Management Review, 21(4), 1022-1054.

Haveman, H. A. (1993). Follow the leader: Mimetic isomorphism and entry into new markets. Administrative Science Quarterly, 38, 593-637.

Higley, J. (2002). AAHOA's expanded vision looks for united industry. Hotel \& Motel Management, 217(9), 1-41.

Johnson, G. (1988). Rethinking incrementalism. Strategic Management Journal, 9(2), 7591.

Kahneman, D., \& Miller, D. (1986). Norm theory: Comparing reality to its alternatives. Psychological Review, 93, 136-153.

Love, L. G., Priem, R. L., \& Lumpkin, G. T. (2002). Explicitly articulated strategy and firm performance under alternative levels of centralization. Journal of Management, 28(5), 611-627.

Miller, D., \& Shamsie, J. (1999). Strategic responses to three kinds of uncertainty: Product line simplicity at the Hollywood film studios. Journal of Management, 25(1), 97-116.

Miller, S. J., Hickson, D. J., \& Wilson, D. C. (1999). Decision-making in organizations, In S. R. Clegg, C. Hardy, \& W. R. Nord (Eds.), Managing organizations: Current issue (pp. 43-62). London: Sage.

Mintzberg, H. (1978). Patterns in strategy formation. Management Science, 24, 934-953.

Mintzberg, H., Ahlstrand, B., \& Lampel, J. (1998). Strategy Safari. New York: Free Press. 
Mintzberg, H., \& Waters, J. A. (1985). Of strategies, deliberate and emergent. Strategic Management Journal, 6, 257-272.

Narayanan, V. K., \& Fahey, L. (1982). The micropolitics of strategy formulation. Academy of Management Review, 7, 25-34.

O’Neill, H. M., Pouder, R. W., \& Buchholtz, A. K. (1998). Patterns in the diffusion of strategies across organizations: Insights from the innovation diffusion literature. Academy of Management Review, 23(1), 98-114.

O'Neill, J. W. (1997). An interorganizational macroculture: The case of all-suite hotels. Journal of Hospitality \& Tourism Research, 21(2), 98-110.

O’Neill, J. W. (2000). Strategic directions of hotel industry executives. FIU Hospitality Review, 18(2), 51-60.

Okumus, F. (2002). Can hospitality researchers contribute to the strategic management literature? International Journal of Hospitality Management, 21(2), 105-110.

Olsen, M. D., \& Roper, A. (1998). Research in strategic management in the hospitality industry. International Journal of Hospitality Management, 17(2), 111-124.

Pfeffer, J. (1981). Management as symbolic action: The creation and maintenance of organizational paradigms. Research in Organizational Behavior, 3, 1-52.

Porac, J. F., \& Thomas, H. (1990). Taxonomic mental models in competitor definition. Academy of Management Review, 15, 224-240.

Quinn, J. B. (1980). Strategies for change: Logical incrementalism. Homewood, IL: Irwin.

Raio, N. (1999). AAHOA survey uncovers points of contention among franchise community. Hotel Business, 8(3), 10-32.

Robert, C., \& Wasti, S. A. (2002). Organizational individualism and collectivism: Theoretical development and an empirical test of a measure. Journal of Management, 28(4), 544-566.

Rosenthal, R., \& Rosnow, R. L. (1991). Essentials of behavioral research: Methods and data analysis (2nd ed.). New York: McGraw-Hill.

Ross, C. (1996). Things are not all-suite. Lodging, 22(3), 61-64.

Simon, H. A. (1957). Administrative behavior (2nd ed.). New York: Macmillan.

Simon, H. A. (1965). The shape of automation. New York: Harper \& Row.

Simon, H. A. (1976). Administrative behavior (3rd ed.). New York: Macmillan.

Simons, T., \& Namasivayam, K. (1999). The eye of the beholder: Hotel company CEO perceptions of threats and opportunities. Journal of Hospitality \& Tourism Research, 23(4), 354-370.

Sims, H. P., Jr., \& Lorenzi, P. (1992). The new leadership paradigm: Social learning and cognition in organizations. Newbury Park, CA: Sage.

Walsh, J. P. (2000). Private equity funds drive hotel market. Hotel \& Motel Management, 215(17), 12-13.

Wheelen, T. L., \& Hunger, J. D. (2002). Concepts in strategic management and business policy (8th ed.). Upper Saddle River, NJ: Prentice Hall.

Whittington, R. (2001). What is strategy—and does it matter? London: Thomson Learning.

Zucker, L. G. (1987). Institutional theories of organization. Annual Review of Sociology, $13,443-464$. 
Submitted September 5, 2003

First Revision Submitted January 28, 2004

Final Revision Submitted April 27, 2004

Accepted April 27, 2004

Refereed Anonymously

John W. O'Neill, Ph.D. (E-mail: jwo3@psu.edu), is an assistant professor in the School of Hospitality Management, at The Pennsylvania State University (233 Mateer Building, University Park, PA 16802); Laura L. Beauvais, Ph.D. (E-mail: beauvais@uri.edu), is a professor in the College of Business Administration, at the University of Rhode Island (36 Upper College Road, Kingston, RI 02881); Richard W. Scholl, Ph.D. (E-mail: rscholl@ uri.edu), is the director at the Schmidt Labor Research Center, at the University of Rhode Island (36 Upper College Road, Kingston, RI 02881). 